\title{
EXPANDING AND DIVERSIFYING THE POOL OF UNDERGRADUATES WHO STUDY ECONOMICS: INSIGHTS FROM A NEW INTRODUCTORY COURSE AT HARVARD
}

\author{
Amanda Bayer \\ Gregory Bruich \\ Raj Chetty \\ Andrew Housiaux \\ Working Paper 26961 \\ http://www.nber.org/papers/w26961 \\ NATIONAL BUREAU OF ECONOMIC RESEARCH \\ 1050 Massachusetts Avenue \\ Cambridge, MA 02138 \\ April 2020
}

We thank Abigail Hiller, Kate Musen, and Nicolaj Thor for excellent research assistance and thoughtful comments. This research was funded by the Bill \& Melinda Gates Foundation, ChanZuckerberg Initiative, and Harvard University. The views expressed herein are those of the authors and do not necessarily reflect the views of the National Bureau of Economic Research.

NBER working papers are circulated for discussion and comment purposes. They have not been peer-reviewed or been subject to the review by the NBER Board of Directors that accompanies official NBER publications.

(C) 2020 by Amanda Bayer, Gregory Bruich, Raj Chetty, and Andrew Housiaux. All rights reserved. Short sections of text, not to exceed two paragraphs, may be quoted without explicit permission provided that full credit, including $\odot$ notice, is given to the source. 
Expanding and Diversifying the Pool of Undergraduates who Study Economics: Insights from a New Introductory Course at Harvard Amanda Bayer, Gregory Bruich, Raj Chetty, and Andrew Housiaux NBER Working Paper No. 26961

April 2020

JEL No. A2

\begin{abstract}
$\underline{\text { ABSTRACT }}$
There is widespread concern that economics does not attract as broad or diverse a pool of talent as it could. For example, less than one-third of undergraduates who receive degrees in economics are women, significantly lower than in math or statistics. This article presents a case study of a new introductory undergraduate course at Harvard, "Using Big Data to Solve Economic and Social Problems," that enrolled 400 students, achieved nearly a 50-50 gender balance, and was among the highest-rated courses in the college. We first summarize the course's content and pedagogical approach. We then illustrate how this approach differs from that taken in traditional courses by showing how canonical topics -income inequality, tax incidence, and adverse selection - are taught differently. Then, drawing upon students' comments and prior research on effective teaching practices, we identify elements of the course's approach that appear to underlie its success: connecting the material to students' own experiences; teaching skills that have social and career value; and engaging students in scientific investigation of real-world problems. We conclude by discussing how these ideas for improving instruction in economics could be applied in other courses and tested empirically in future research.
\end{abstract}

\begin{tabular}{|c|c|}
\hline Amanda Bayer & Raj Chetty \\
\hline Swarthmore College & Department of Economics \\
\hline abayer1@swarthmore.edu & Harvard University \\
\hline & Littauer 321 \\
\hline Gregory Bruich & Cambridge, MA 02138 \\
\hline Department of Economics & and NBER \\
\hline Harvard University & chetty@fas.harvard.edu \\
\hline Littauer 113 & \\
\hline Cambridge, MA 02138 & Andrew Housiaux \\
\hline gbruich@fas.harvard.edu & Tang Institute \\
\hline & Phillips Academy \\
\hline & 180 Main Street \\
\hline & Andover, MA 01810 \\
\hline
\end{tabular}

Course Materials are available at www.opportunityinsights.org/course 


\section{Introduction}

There is widespread concern that the field of economics does not attract as broad or diverse a pool of talent as it could. Women and members of historically underrepresented racial and ethnic minority groups are strikingly absent from undergraduate economics classrooms. For example, women earned only 28.4\% of bachelor's degrees in economics in 2014, compared with $42.6 \%$ of degrees in mathematics in statistics (Bayer and Rouse 2016, Bayer and Wilcox 2019). Moreover, while other fields such as computer science and statistics have experienced substantial growth in enrollment in recent years, both overall and among women, enrollment in economics has stagnated and the gender share has not changed significantly over the past three decades (Department of Education 2018; Avilova and Goldin 2018).

One potential reason for these demographic imbalances and limited growth in enrollments may be that students misunderstand what economics is and the range of topics that economists address. Women are more than twice as likely as men to report that they did not take economics in their first year of college because they "did not think that economics was interesting” (Dynan and Rouse 1997). Anecdotally, many economists share the experience of being asked to predict the stock market after telling someone they are an economist, reflecting the general public's misconceptions about what economists do. In light of such evidence, Bayer and Rouse (2016) suggest that changing the way that economics is taught to undergraduates may be an effective lever for increasing the supply of diverse talent in the field.

In this article, we present a case study of a new introductory course at Harvard that took up this challenge and attracted a large and diverse student body. The course, titled "Using Big Data to Solve Economic and Social Problems,” was taught by Raj Chetty and Gregory Bruich beginning in Spring 2019. ${ }^{2}$ It provides an empirically-grounded introduction to economics without any prerequisites and was offered as an elective intended to complement traditional principles courses. Unlike traditional economics courses that are organized primarily around a set of theoretical principles, this course is organized around a set of policy-relevant topics - such as inequality, climate change, and health insurance - and teaches empirical methods and theories as tools to tackle those questions. ${ }^{3}$ Instead of using a textbook, the course presents a set of research papers that exploit modern big data to shed light on these topics. The course also engages students in doing economics through labs and empirical research projects rather than problem

\footnotetext{
${ }^{2}$ Chetty first taught an abbreviated (one quarter) version of the course at Stanford in 2017; we focus here on the full length (one semester) version of the course taught at Harvard in Spring 2019 and Spring 2020. Combining the Stanford and Harvard courses, nearly 1,000 students have now taken the class.

${ }^{3}$ As Chetty says in his opening lecture of the course, "Fundamentally, we want to start from the questions that motivate the methods we teach in economics and social science, rather than the traditional approach, which is to do the reverse.... What we're trying to do is turn [the traditional approach to teaching economics] on its head and start out with the questions that we think can be solved if you learn these tools.” (Chetty 2019)
} 
sets, much as laboratory-based science classes engage students in doing scientific experiments themselves.

The course was among the largest at Harvard: it had 375 students in Spring 2019 and 400 students in Spring 2020. Many of these students were new to economics: 74\% were either undeclared first-years or students majoring in a field other than economics. Moreover, the course achieved a near 5050 gender balance, with a larger fraction of women than any other class taught in the economics department, including the traditional introductory economics courses (Economics 10), which had 42\% women (macroeconomics) and 44\% women (microeconomics), as shown in Figure 1a. ${ }^{4}$ The course was very favorably reviewed - ranking among the highest-rated large undergraduate courses at Harvard - with many students remarking that it was one of the most inspiring classes they had taken and that it reshaped their interests going forward.

The purpose of this article is to explore why this new course succeeded in exposing a large and diverse new group of students to economics, with the aim of identifying lessons that can be applied in other institutions and courses. We begin by describing the course's approach and showing how it differs from those traditionally taken in economics courses, using its treatment of three canonical topics inequality, tax incidence, and adverse selection - as illustrative examples. Then, drawing upon prior work on effective teaching practices as well as information from students' comments, we identify five potentially generalizable elements of the course that appear to drive its success: personal connection (exploring conditions students face in their own lives), real-world exposure (analyzing real-world problems rather than hypothetical examples or abstract ideas), social value (teaching skills that have social impact), career value (teaching skills valued by potential employers), and scientific inquiry (engaging students in the process of scientific discovery).

As a concrete example, in the context of teaching about inequality and income distributions, the course invites students to explore the Opportunity Atlas - an interactive web-based tool that allows students to explore social mobility by Census tract across the United States. Students are asked to compare rates of social mobility in their home neighborhood to those in surrounding areas and consider how their lives might have been different had they grown up down the street in a different family. This approach differs from more traditional approaches of presenting macroeconomic statistics and discussing theories for inequality on each of the dimensions described above: it personalizes the subject, connects it to real-world policy questions on segregation and affordable housing, teaches data analysis skills that can

\footnotetext{
${ }^{4}$ The course also had a share of underrepresented minorities (17\%) that was similar to share of underrepresented minorities in the college (20\%), which did not differ significantly from the overall economics department average or the traditional introductory courses (Figure 1b).
} 
be applied to a variety of problems, and invites students to engage in economic analysis themselves by examining the determinants of mobility in their hometown.

We conclude that changing the way introductory economics is taught - in a manner that is relatively straightforward and scalable - can potentially help to attract a larger and more diverse group of students to the discipline. In particular, engaging students with the actual work that economists do by beginning with topics of current interest and presenting methods and principles as tools to answer those questions appears to inspire students to realize the power of the discipline and appreciate its relevance from a personal, career, and social perspective. ${ }^{5}$

This paper contributes to and builds upon a rapidly growing literature analyzing how we can increase diversity in economics, reviewed in Bayer and Rouse (2016). Perhaps most germane is recent work showing that women and minority students are deterred from economics by implicit or explicit messages about the identity of who belongs in the field. For example, Bayer, Bhanot, Bronchetti, and O’Connell (2020) find that, after taking an introductory economics class, women and minority students are less likely to report feeling comfortable asking questions in class, believing that people like them can become economists, and believing that they could learn the material. Porter and Serra (2019) show that exposing women in undergraduate economics courses to successful women who majored in economics significantly increased the fraction of women who chose to major in economics. Bayer, Bhanot, and Lozano (2019) show that providing incoming college students with information showcasing the diversity of research and researchers within economics substantially increases the likelihood that women and underrepresented minorities complete an economics course in their first semester of college.

Our focus on improving the content and pedagogy of introductory economics courses complements and can potentially amplify these efforts to change how economics is perceived. By teaching economics in a way that women find interesting and relevant on a large scale, one may eventually change perceptions of the field more broadly, thereby increasing interest in enrolling in economics courses to begin with. In the future, the increasing prevalence of women in economics could itself produce a virtuous cycle, whereby more women pursue the field because they see more women already in economics. Given that the approach of a course can be controlled almost entirely by economists themselves, we view the changes proposed here as potentially being a particularly powerful leverage point for increasing diversity in the field going forward.

The course we discuss here is by no means the only effort to change the way economics is taught. There are several recent initiatives and textbooks in economics that take somewhat similar approaches,

\footnotetext{
${ }^{5}$ We caution, however, that we do not offer any formal empirical tests of this hypothesis. Rather, we hope that the ideas put forth here based on our own understanding of the course, prior work on effective pedagogy, and students' reactions will provide a useful set of hypotheses to test in future work.
} 
focusing on practical skills to tackle real-world problems (e.g., CORE Economics Team 2017, Stevenson and Wolfers 2020). In addition, recent work has demonstrated that applying research-based pedagogical principles from the cognitive science literature in introductory economics courses greatly increases student learning (Boyle and Goffe 2018). We view this class as complementary to these efforts and part of what will hopefully be a broader shift in the way the discipline is introduced to students.

The rest of the article proceeds as follows. In Section II, we describe the course's structure and content in detail. Section III provides specific examples of the course's approach by showing how its treatment of canonical topics differs from traditional approaches. In Section IV, we discuss the course's approach as it relates to prior work on effective teaching practices and identify key elements of the teaching approach that might explain the course's success. We conclude in Section V by summarizing lessons that could be applied in other institutions and settings. Teaching materials for the course including a syllabus, lecture slides, videos, and empirical projects - are freely available at opportunityinsights.org/course.

\section{Course Structure and Content}

The idea for teaching "Using Big Data to Solve Economic and Social Problems” (which we refer to hereafter as "Social Problems") occurred to Chetty in the context of non-technical lectures that he was giving to the general public (non-profit convenings, schools, TEDx talks) about his lab’s research on equality of opportunity. These talks covered recent research papers focused on improving opportunities for upward mobility in a manner that was accessible to audiences with no training in economics. These presentations invariably generated tremendous interest, with many remarking that they felt inspired by the material. Most surprising was a frequent reaction by audience members that they "had no idea that this is what economists do,” and had they known, they “would have studied this in college!”

Motivated by these experiences, Chetty began to design a set of lectures that emulated the style of these non-technical talks, starting up front with questions of current interest and then drawing students into the research process of discovery and learning through this lens. After developing an initial set of lectures, Chetty began collaborating with Bruich to expand the course content and supporting learning material, including labs and empirical projects. The course was the first class in Harvard's Department of Economics that did not require the standard year-long introductory economics class (Economics 10) as a prerequisite, so it truly was a new and distinct entry point into the field. ${ }^{6}$

\footnotetext{
${ }^{6}$ Econometrics courses (Economics 1123 taught by James H. Stock and Gregory Bruich and Economics 1126 taught by Elie Tamer) at Harvard do not require Economics 10, but do have other statistics or mathematics prerequisites.
} 
Here, we present a short summary of the Social Problems course as it was taught in Spring 2020 at Harvard (see the course syllabus for complete details). The course was taught with a combination of lectures (large sessions with 400 enrolled students and about 50 auditors) and small labs led by teaching fellows (with 15-20 students each). The curriculum can be adapted to other settings (e.g., omitting the labs) using the resources described in the conclusion.

Lectures. The lectures are organized around broad topics such as: inequality and social mobility, education, tax policy, criminal justice, climate change, and health. Each topic begins with a broad question (e.g., "How can we help more low-income children achieve the American Dream of upward income mobility?”), which is followed by descriptive evidence characterizing the problem (e.g., showing that children's chances of earnings more than their parents have fallen dramatically over the past half century in the U.S.), before turning to empirical studies examining the drivers of the problem. The lectures draw almost entirely on research papers written within the past 5-10 years; as a result, there is no textbook for the class and students are encouraged to read subsets or non-technical summaries of the papers covered in lecture.

In the context of the broad topics, students are introduced to empirical and theoretical methods that are relevant for the questions at hand. For example, students are taught regression discontinuity methods in the context of learning about Fredriksson et al.'s (2013) analysis of the effects of class size on children's long-term outcomes; they are taught about the principles of supply and demand and competitive equilibrium in the context of a paper by Bergman et al. (2020) studying low-income families' neighborhood choices in Seattle. Each lecture presents at least one methodological concept, so that by the end of the course students have been exposed to a broad array of statistical methods, ranging from noncompliance in randomized experiments to propensity score reweighting to the basic idea of machine learning, as well as a variety of microeconomic principles, ranging from incentive effects to equilibrium to adverse selection.

Five of twenty-six lectures during the semester are structured as discussions with guest speakers who illustrate how the research being covered in class shapes economic and social policy in the real world. These speakers include practitioners such as Shaun Donovan, who discussed how research on neighborhood effects and economic mobility had transformed the Housing and Urban Development Agency's approach, and Geoffrey Canada, founder of the Harlem Children's Zone, who discussed how low-income Black children's outcomes were dramatically improved in Harlem through targeted, placebased investments. They also include leading economists and social scientists such as Esther Duflo, who spoke about how empirical evidence in the age of big data transformed immunization programs in India. 
Despite the large size of the lectures, students are encouraged to ask questions throughout, and roughly $20 \%$ of the lectures are spent responding to questions. Students also frequently participate in electronic polls during lecture to increase engagement.

Labs. The lectures give students a broad overview of how economic research is done, but their size limits students' ability to engage in actually doing economics themselves. The labs, staffed by approximately 20 teaching fellows (typically Ph.D. students), provide a smaller, interactive environment. The labs meet once a week for 75 minutes, during which students work on their computers with real data to learn how to implement the methods discussed in lecture themselves (e.g., write code to estimate the treatment effect of an experiment). Again, the datasets used are real data (simplified and cleaned for an introductory course) and are motivated by real-world problems being asked in current research papers. For example, the lab accompanying the lectures on intergenerational mobility focused on replicating statistics from Chetty et al.'s (2014) analysis of the geography of intergenerational mobility using publicly-available data from the National Longitudinal Survey of Youth. Students estimated different measures of mobility, summarized their conceptual meaning, and learned basic skills such as data visualization and basic statistical measures of central tendency, dispersion, correlation, and regression. Students familiar with such concepts from prior courses were assigned to a separate set of labs that focused on more advanced topics, thereby allowing each student to engage at a level matching their current skill set.

To further increase opportunities for students to engage with the teaching staff, labs are supplemented with extensive office hours to assist with coding and questions, as well as a web-based chat interface that allows students to post questions and see others' questions and answers from teaching fellows. Students are also invited to small group lunches and dinners with the professor that give them a chance to connect more informally and engage in greater depth on topics that interest them.

Empirical Projects. The central work done by students outside the classroom consists of four empirical projects that seek to put students in the shoes of a social scientist. These projects entail coding, reading papers, and writing up results on a policy question and are significantly more substantial than standard problem sets. Each project focuses on a specific empirical method and uses data from a recent paper to replicate and expand upon analyses done by researchers. The four projects (along with the methods they covered) assigned in Spring 2020 were:

1. Stories from the Opportunity Atlas [Descriptive Data Analysis]

2. Effects of Housing Vouchers on Neighborhood Choice [Randomized Experiments]

3. Effects of Class Size on Students' Educational Outcomes [Regression Discontinuity]

4. Targeting Programs to Reduce Rate of Low-birthweight Babies [Machine Learning] 
These empirical projects are supplemented with more frequent short assignments that engage students in thinking about key concepts and debates. For example, in one of these shorter assignments, students interviewed a classmate who has a different view on a relevant issue, such as whether colleges should pursue strictly merit-based admissions or offer affirmative action to children from low-income families, and wrote up a summary of their classmates’ views and their own reactions.

\section{Contrast with Traditional Courses: Illustrative Examples}

In this section, we further elucidate the approach taken in the Social Problems course by contrasting it with the approach taken in traditional economics courses. To do so, we focus on three canonical topics that are covered in most introductory courses - income distributions and inequality, tax incidence, and adverse selection - and show how they are taught in the Social Problems course.

\section{III.A Introducing Inequality Through the Opportunity Atlas}

Most introductory economics courses include some discussion of income distributions and inequality. A common approach to presenting this material is to start with basic macroeconomic facts about the evolution of wage rates, income distributions, and intergenerational mobility over time, and then to discuss theoretical explanations for why inequality has grown in recent decades in most developed countries, such as skill-biased technical change, pressures from global competition, or the decline of labor unions.

The Social Problems course approaches these topics differently, by seeking to personalize issues of inequality and engage students in studying inequality and social mobility themselves using real data. The very first slide of the course introduces students to the idea of the "Fading American Dream" - the result that children's chances of earning more than their parents have fallen dramatically in America over the past fifty years. Students are then asked to think about why this may have happened, and are introduced to research that uses data drawn from anonymized tax and Census records to reveal how rates of upward mobility vary across areas within the United States. Students are presented with various alternative hypotheses for this variation - ranging from differences in segregation to racial disparities to differences in family structure - and are shown how researchers are currently going about testing between these explanations. In the process of learning these topics, students are introduced to key statistical concepts such as descriptive statistics, correlation, and regression as well as economic ideas such as steady states of dynamic systems in a simple, intuitive manner. 
A key tool used in this part of the class is the Opportunity Atlas (www.opportunityatlas.org), a free, interactive tool that allows students to explore rates of upward income mobility across generations by Census tract (see Figure 2 for a snapshot of upward mobility in the Los Angeles area). The first assignment of the course asks students to work with the Opportunity Atlas data to explore rates of upward mobility in their hometown (or another community of interest), and to consider how their own prospects and outcomes might have differed had their family happened to live in another part of town. Students formulate and test hypotheses about what drives differences in upward mobility across the neighborhoods in their hometown.

The Opportunity Atlas exemplifies the personalized, inquiry-based approach that is at the heart of the Social Problems course. For many students, this is literally the first time they engage in any data analysis. To ease them into unfamiliar territory, students begin by using the interactive Atlas website. They then work with the raw data using Stata or R, guided by teaching fellows in their labs. Students are taught enough programming to work with the data set. As Chetty (2019) noted in his opening lecture, "the goal is not to teach you every method and teach you all the different concepts in one class.” Instead, students learn just what they need to know to answer the questions at hand, gradually increasing sophistication and complexity as the course progresses.

Students apply their growing understanding of key concepts to the data about their chosen community. They learn how to visualize data through creating maps and graphs. The final part of this project asks students to write a narrative summarizing their findings in response to this prompt:

Putting together all the analyses you did above, what have you learned about the determinants of economic opportunity where you grew up? Identify one or two key lessons or takeaways that you might discuss with a policymaker or journalist if asked about your hometown. Mention any important caveats to your conclusions; for example, can we conclude that the variable you identified as a key predictor in the question above has a causal effect (i.e. changing it would change upward mobility) based on your analysis? Why or why not?

By asking students to synthesize their learning and reflect on the limitations of their analysis, this assignment emphasizes the importance of deep understanding. Linking the approach to a student's hometown (or a community of interest) enables students to better recall and visualize the place they study, bringing first-person experience into dialogue with statistical and economic analysis. Finally, because the responses are written to engage a new (hypothetical) audience, students demonstrate their understanding in a manner that does not ask them to merely recapitulate what they learn in class; rather, they are motivated to create something novel.

The unit on opportunity concludes by showing students how the tools and concepts covered in class are directly impacting economic policy today, informing issues from how the federal government 
and cities approach affordable housing policies to the design of schools. Students see how the type of work they themselves had participated in makes a real difference in the world.

This approach to teaching inequality differs from more traditional approaches, because it shows students that they can research - and perhaps even make a difference in - problems as real and complex as economic inequality. In contrast, traditional approaches may leave students feeling that they have learned about a set of important facts and theories, but feeling less empowered to make a difference on these issues. Indeed, many students report they leave the course inspired to return to their hometowns to try to address the stark disparities they learned about through the Opportunity Atlas.

\section{III.B Tax Incidence}

The theory of tax incidence describes how prices adjust in response to a tax in market equilibrium. The key question is: are taxes that are statutorily levied on producers passed through to consumers in the form of higher prices? Or, do producers bear the burden themselves in the form of reduced profits? Economic theory predicts that the answer to this question will depend on the relative elasticities of supply and demand, with the more inelastic side of the market bearing more of the incidence of the tax.

The traditional way to teach these concepts is to begin with a stylized, abstract model of a particular market in the economy and show how, when a tax is levied, demand or supply curves shift and the equilibrium price adjusts graphically and algebraically. Students are shown how one can solve for equilibrium prices before and after the tax is imposed, and how the solution is a function of supply and demand elasticities. This theoretical introduction is then sometimes followed with empirical examples of incidence in real markets.

The Social Problems course reverses the order of this presentation by starting from an applied policy question, showing empirical results, and then explaining the theory behind those results. Students in the Social Problems course learn tax incidence theory as a tool that can be helpful in studying policies to mitigate climate change. In this context, the key policy question is whether or not gasoline taxes would be an effective policy tool for mitigating climate change. If the incidence of gasoline taxes fell entirely on producers and did not result in higher prices for consumers, policymakers would have limited scope to influence consumer demand - hence the importance of understanding the incidence of the tax.

To analyze this question, students first examined graphical evidence from a paper by Doyle and Samphantharak (2008) on the impact of gas tax holidays in Indiana and Illinois on gasoline prices. Students learned that by comparing changes in prices in these states to the changes in prices in surrounding states (as shown in Figure 3), economists use difference-in-differences estimators to determine the causal effect of taxes on prices. Students learned the key identification assumption needed 
for this empirical method, and how to assess whether it is plausibly satisfied in the data (by checking for parallel trends before the reform).

Doyle and Samphantharak find that, on average, a 10-cent increase in state gasoline taxes leads to roughly a 7-cent increase in the price consumers pay at the pump. Furthermore, they show that consumers living near state borders bear less of the incidence of the tax than those living in the interior. This heterogeneity provides a simple hook for explaining the theory of tax incidence to students. Why do consumers bear less of the pain from tax increases if they live near state borders? The intuitive reason is that these consumers can easily drive across the border to the state that did not raise its tax if gas stations attempt to pass the price increase on fully to consumers. This idea that consumers who can "get away" from taxes bear less of the burden illustrates the key concept that more elastic factors bear less tax incidence, a result that can now easily be taught using graphical supply-demand diagrams.

This approach to teaching tax incidence generates interest in the context of a topic that many students are passionate about (climate change) and brings an abstract concept alive in the context of realworld data. The advantage relative to the traditional approach of starting with the theory of tax incidence and then presenting applications is that students are eager to learn the tools from the outset and thus engage more deeply in the material.

\section{III.C Adverse Selection}

Adverse selection refers to the idea that information asymmetries between buyers and sellers can potentially lead competitive markets to unravel. A traditional approach to teaching adverse selection begins with a stylized model of buyers and sellers of a good (e.g., used cars) and shows how markets can unravel in the presence of hypothetical information asymmetries. The stylized example is then sometimes followed by specific examples of markets that have unraveled.

In the Social Problems course, this ordering is again reversed. The concept of adverse selection is introduced in a unit on health insurance, in the context of evaluating the impacts of universal health insurance programs. The key question here is whether we can simply rely on the market to provide health insurance as it does other goods or if health insurance markets require government intervention to function well. As a real-world entry point for studying these issues, students examined graphical evidence from a recent paper by Finkelstein, Hendren, and Shepard (2019) that empirically analyzed the universal health insurance coverage reform in Massachusetts in 2006. This program provided subsidies for health insurance that were a discontinuous function of income. Exploiting a regression discontinuity research design, the authors show with a simple graph (replicated in Figure 4) that individuals who faced higher prices were less likely to buy insurance. Critically, it was the healthiest (lowest-cost) individuals who 
dropped out of the market first. This intuitive result captures the idea of adverse selection, and seeing this pattern in the data immediately made the concept obvious to students. Building on this logic, students were taught how markets could unravel as prices spiraled upward as healthier individuals dropped out. To empirically ground this claim, students are presented with a second empirical example where such unravelling actually occurred in the employee health plan at Harvard University (Cutler and Reber 1998). Finally, these results are used to shed light on current health care policy debate.

This example again captures the essence of the Social Problems course's teaching method. Through a real-world topic of current social interest - the provision of health insurance - students learn both a core economic principle (adverse selection) and statistical method (regression discontinuity) as tools that are useful to shed light on the motivating question. By ensuring that students are well-motivated to learn the methods and conveying the key concepts in simple, graphical terms with limited technical jargon, one sparks engagement and learning even among students with no prior background knowledge.

\section{General Lessons from the Course's Approach}

In this section, we build on the examples above and attempt to distill the key elements of the Social Problems course that explain its success, with the aim of offering generalizable insights that could be applied in other institutions and courses. We begin by briefly reviewing lessons from prior work about courses that are effective in engaging students from diverse backgrounds. Then, guided by information from student evaluations, we identify five key elements of the Social Problems course that mirror the themes identified in the prior work.

Research on effective teaching practices consistently finds that the most effective courses engage students in scientific inquiry about real-world questions through "learning by doing." Mehta and Fine (2019a) visited thirty high schools across the United States to characterize the types of classes that were most effective. They report that:

The truly powerful core classes that we found...echoed what we saw in extracurriculars. Rather than touring students through the textbook, teachers invited students to participate in the authentic work of the field. For example, a skillful science teacher in a highpoverty-district high school offered a course in which her students designed, researched, carried out and wrote up original experiments. While the experiments varied in their sophistication, all students were initiated into what it meant to do science.

The empirical literature on effective and inclusive teaching delivers a similar message: the best way to engage students is to involve them actively in their own learning. Classes in which students learn actively — through techniques such as problem-solving, discussion, think-pair-share, and peer instruction —increase student performance on assessments by half a standard deviation relative to "teaching by 
telling” approaches where students learn more passively (Freeman et al. 2014). Active learning also reduces achievement gaps for women and students from disadvantaged backgrounds in STEM fields (e.g., Lorenzo, Crouch, and Mazur 2006, Haak, HilleRisLambers, Pitre, and Freeman 2011; Theobald et al. 2020). Similarly, Matz et al. (2017) find that "biology, chemistry, physics, accounting, and economics lecture courses regularly exhibit gendered performance differences that are statistically and materially significant, whereas lab courses in the same subjects do not.”

Perkins (2010) uses the analogy of baseball to illustrate the idea of learning by doing. As a child, he says, he did not learn to play baseball through lectures on the history of sport, or through repetitive drills on specific aspects of the game; instead, he recalls, "from the beginning, I built up a feel for the whole game" by playing the game at an accessible level. He notes that the essence of baseball can be understood and played from even a young age; as children mature, they will play more sophisticated versions of the same game. What is important is that from the very outset, the essential components are there - a child is playing baseball from the very beginning.

Learning by doing is a signature aspect of the Social Problems course, in which students are encouraged to do economics. The course approaches economics like a lab science, where students are asked to engage with hands-on work to build knowledge themselves rather than solely learning longestablished principles. ${ }^{7}$ Students apply the scientific method, use economic and statistical models, and communicate their results - all essential competencies fundamental to the discipline of economics according to the Social Science Research Council (Allgood and Bayer 2016). Crucially, in order to empower introductory-level students to engage themselves in true economic analysis, extensive effort is put into developing ways to teach what might be perceived as complex material in an intuitive, nontechnical manner.

In addition to 'learning by doing,' Mehta and Fine (2019b) go on to describe three further characteristics of classrooms tend to that foster deep learning: mastery, identity, and creativity.

In the spaces that teachers, students, and our own observations identified as the most compelling, students had opportunities to develop knowledge and skill (mastery), they came to see their core selves as vitally connected to what they were learning and doing (identity), and they had opportunities to enact their learning by producing something rather than simply receiving knowledge (creativity).

Again, the Social Problems course shares these characteristics. Students develop the mastery required of economists as they learn methods and immediately apply them to social issues like inequality and climate change. For example, in the Opportunity Atlas assignment, the focus on the student's hometown increases relevance and intrinsic motivation: identity. In the unit on education, students examine data on the

\footnotetext{
${ }^{7}$ By eschewing a textbook in favor of recent research papers, the course demonstrates to students that economics is a field that is alive and not just an inflexible body of knowledge.
} 
parental income distributions of students at Harvard - again directly connected to their personal experience.

Students did not just memorize algebraic or statistical models and solve problems with slightly different variables and values. Instead, they learned how to approach data sets and problems like an economist. They played the whole game at a junior level, learning deeply as they undertook intellectual work that was meaningful to the field and addressed centrally relevant concerns of their own lives, developing a personal connection to the work.

These themes - scientific inquiry, real-world problems, and personal connection - are reflected in students' course evaluations. Notably, the word "personal” in the course comments was universally used in a positive context in the Social Problems course evaluations (e.g., "I enjoyed the personal aspect of analyzing your own neighborhood”), whereas in other introductory courses students often used it negatively (e.g., describing the course as "impersonal”). Students also commented on how the course allowed them to engage with real world issues, ("I learned economics theory and methods AND got to apply them to extremely important issues, all within the scope of one class.”) and they described enjoying the opportunity to engage in scientific inquiry. ("The projects were great opportunities to use real techniques in analyzing actual data.”)

In addition to these themes, several students also remarked on the direct value of the skills they learned in the class, both from a career perspective ("This course has encouraged me to explore careers in the area of big data and tech towards social good.") and in terms of social relevance ("Economics is a very powerful tool when trying to tackle big issues in the world.”). Students consistently described feeling inspired by the material to think more broadly about the impact they could have in the world using the tools of economics and statistics. One student remarked:

This is one of the best courses I have taken at Harvard. I love that the methods and economic concepts were integrated with the issues. I hadn't been interested in taking economics before, but the fact that this class started with issues I care about and taught the rest through them made it awesome!

This quote captures the course's approach of teaching economic theory and statistical methods as needed to understand the topics. Because the tools are being taught as solutions to problems that they find important, students find themselves highly motivated to learn the topics and the methods. 
Putting together what we learn from connecting the course’s approach to the prior literature and the student evaluations, we identify five key mechanisms that appear to drive the course's success in attracting a large group of diverse students who were inspired by the class:

\section{Five Key Elements of the Course's Approach}

Personal connection: The course examines issues that have been experienced by the student or people in their community.

Real-world exposure: The course exposes students to current real-world problems.

Scientific inquiry: The course encourages inquiry and investigation.

Career value: The course teaches content and skills that are likely to be valued by future employers.

Social value: The course teaches content and skills relevant to helping other people and society.

It is also worth remarking on themes that are sometimes discussed in the profession but were not mentioned frequently in course evaluations. Some instructors express concerns about the degree of quantitative material (math or statistics) in courses or on the overall "difficulty" of the class as drivers of student engagement and interest. But neither of these issues was salient in the course comments; indeed many students remarked that the course challenged them to learn new quantitative and coding skills but they came away happy they took up the challenge. This is consistent with prior research showing that mathematical aptitude or the sheer difficulty of classes does not appear to be a central explanation for why certain groups of students are underrepresented in economics (e.g., Bayer and Rouse 2016).

\section{An Aside: Why "Big Data"?}

Readers will note that what we have discussed this far about the course's approach does not inherently have anything to do with "big data” per se; yet "Big Data” appears in the course's title. We believe that the course's approach is facilitated in several key respects by its use of big data - by which we mean large datasets that have numerous observations and/or variables.

First, datasets with large numbers of observations - such as Census or tax records covering the entire population - enable simple graphical analyses that allow students without prior training in the field to visualize patterns in the data with clarity and ease. For example, when teaching students about intergenerational mobility, it is straightforward to non-parametrically plot the relationship between parent and child income by showing the conditional mean of children's incomes in each parental income 
percentile. This approach of non-parametric data visualization reduces the need to go through the technical details of statistical methods such as regression or correlation, which would be necessary to reduce dimensionality in smaller datasets. Indeed, most of the statistics presented in the class are essentially carefully constructed conditional means (e.g., means conditioned on the running variable in regression discontinuity designs). This enables even students with no prior experience in statistics or econometrics to quickly start engaging in the research and data themselves.

Second, and equally important, big data enables the content to be more personal to students. With large enough datasets - like the dataset that underlies the Opportunity Atlas - students can explore patterns for their own demographic group, neighborhood, or college. Naturally, with smaller surveybased datasets, it is difficult if not impossible to personalize empirical analyses in this way.

\section{Conclusion}

How can we expand and diversify the pool of students who choose to study economics? In this paper, we presented a case study of a new introductory course at Harvard that successfully attracted a large number of new students to the field who - unlike typical economics students - were representative of the college's demographics in terms of gender, race, and ethnicity. Our analysis of this course in connection with prior research on effective teaching practices and students' comments suggests that changes in courses' content and pedagogical approaches can have a substantial impact on interest in the field. In particular, we identify five key elements - personal connection, real-world exposure, scientific inquiry, career value, and social relevance - that we believe are valuable in engaging students in economics.

Going forward, we see two paths to scaling this approach to teaching economics to other colleges, and even high schools. Firstly, the materials used in the Harvard course can be directly incorporated into other introductory courses. To facilitate such adoption, we have made all of the course materials syllabus, lecture videos, slides, and notes, empirical projects, and labs - freely available online at www.opportunityinsights.org/course. Additionally, we have initiated a network of college and high school partners who have expressed interest in teaching this material (if you are interested in joining this network, email info@opportunityinsights.org). We are also working to incorporate modules of the course at the high school level, starting with a pilot at Phillips Andover Academy in the 2019-2020 academic year.

Second, and more broadly, the key elements of the approach taken in the Social Problems course can be incorporated into other undergraduate courses that traditionally draw relatively few women and underrepresented minorities, such as finance, industrial organization, and macroeconomics. Regardless of subject matter, instructors can design courses that offer opportunities for students to connect the material 
to their own personal experiences, actively engage them in the process of scientific inquiry, and demonstrate how the knowledge developed in the course can be useful in their careers and society. To accomplish this, instructors could begin from the major topical questions of the field and then introduce methods as relevant to those topics in a manner that minimizes technical jargon. By giving students the opportunity to engage with the exciting work that economists are currently doing in these areas, instructors may be more likely to inspire students to continue that line of inquiry themselves.

Finally, from a research perspective, it would be useful to test the hypothesis that changing the way introductory courses are taught along the five dimensions we identify here increases student engagement and interest in studying and pursuing economics. Such work can allow us to isolate which of these elements are most impactful and thereby permit more effective improvements in teaching that can be applied on scale, which is likely to be critical for expanding the supply of talent in the field in the long run. 


\section{References}

Allgood, S., and A. Bayer. 2016. Measuring College Learning in Economics. In Improving Quality in American Higher Education: Learning Outcomes and Assessments for the 21st Century, ed. R. Arum, J. Roksa, and A. Cook, 87-134. San Francisco: Jossey-Bass. doi: 10.1177/2332858417743754.

Avilova, T., and C. Goldin. 2018. What Can UWE Do for Economics? AEA Papers and Proceedings 108:186-190. doi: 10.1257/pandp.20181103.

Bayer, A., and S. P. Bhanot, E. Bronchetti. and S. O’Connell. 2020. Diagnosing the Learning Environment for Diverse Students in Introductory Economics: An Analysis of Relevance, Belonging, and Growth Mindsets. American Economic Review Papers and Proceedings.

Bayer, A., S. P. Bhanot, and F. Lozano. 2019. Does Simple Information Provision Lead to More Diverse Classrooms? Evidence from a Field Experiment on Undergraduate Economics. AEA Papers and Proceedings 109: 110-14. doi: 10.1257/pandp.20191097.

Bayer, A., and C. E. Rouse. 2016. Diversity in the Economics Profession: A New Attack on an Old Problem. Journal of Economic Perspectives 30 (4): 221-42. doi: 10.1257/jep.30.4.221.

Bayer, A., and D. W. Wilcox. 2019. The Unequal Distribution of Economic Education: A Report on the Race, Ethnicity, and Gender of Economics Majors at U.S. Colleges and Universities. Journal of Economic Education 50 (3): 1-22. doi: 10.1080/00220485.2019.1618766.

Bergman, P., R. Chetty, S. DeLuca, N. Hendren, L. Katz, and C. Palmer. 2020. Creating Moves to Opportunity: Experimental Evidence on Barriers to Neighborhood Choice. NBER Working Paper Series 26164. doi: $10.3386 / \mathrm{w} 26164$.

Boyle, W., and W. L. Goffe. 2018. Beyond the Flipped Class: The Impact of Research-Based Teaching Methods in a Macroeconomics Principles Class. AEA Papers and Proceedings 108: 297-301. doi: 10.1257/pandp.20181052.

Chetty, R. 2019. The Geography of Upward Mobility in America. Lecture at Harvard University. 29 January. https://www.youtube.com/watch?v=P0NvsWDKwvs\&feature=youtu.be

Chetty, R., N. Hendren, P. Kline, and E. Saez. 2014. Where is the Land of Opportunity? The Geography of Intergenerational Mobility in the United States. The Quarterly Journal of Economics 129(4): 15531623. doi: 10.1093/qje/qju022.

CORE Economics Team. 2017. Core Econ: Economics for a Changing World. https://www.coreecon.org/

Cutler, D. M., and S. J. Reber. 1998. Paying for Health Insurance: The Trade-Off between Competition and Adverse Selection, The Quarterly Journal of Economics 113(2): 433-466. doi: $10.1162 / 003355398555649$.

Department of Education 2018. Table 505.10: Number, percentage distribution, unemployment rates, and median earnings of 25-to 29-year-old bachelor's degree holders and percentage of degree holders among all 25-to 29-year-olds, by field of study and science, technology, engineering, or mathematics (STEM) status of field: 2010 and 2017. Digest of Education Statistics, 2018. 
Doyle Jr., J. and K. Samphantharak. 2008. \$2.00 Gas! Studying the Effects of a Gas Tax Moratorium. Journal of Public Economics. 92 (3-4): 869-884. doi: 10.1016/j.jpubeco.2007.05.011.

Dynan, K. E., and C. E. Rouse. 1997. The underrepresentation of women in Economics: A study of undergraduate economics students. Journal of Economic Education 28(4): 350-68. doi: 10.3386/w5299.

Finkelstein, A., N. Hendren, and M. Shepard. 2019. Subsidizing health insurance for low-income adults: Evidence from Massachusetts. American Economic Review 109 (4): 1530-67. doi: 10.3386/w23668.

Freeman, S., S. L. Eddy, M. McDonough, M. K. Smith, N. Okoroafor, H. Jordt, and M. P. Wenderoth. 2014. Active learning increases student performance in science, engineering, and mathematics.

Proceedings of the National Academy of Sciences 111(23): 8410-8415. doi: 10.1073/pnas.1319030111.

Fredriksson, P., B. Öckert, and H. Oosterbeek. 2013. Long-term effects of class size. The Quarterly Journal of Economics 128(1): 249-285. doi: 10.1093/qje/qjs048.

Haak, D. C., J. HilleRisLambers, E. Pitre, and S. Freeman. 2011. Increased structure and active learning reduce the achievement gap in introductory biology. Science 332 (6034): 1213-16. doi:

10.1126/science.1204820.

Lorenzo, M., C. H. Crouch, and E. Mazur. 2006. Reducing the gender gap in the physics classroom. American Journal of Physics 74(2): 118-122. doi: 10.1119/1.2162549.

Matz, R. L., B. P. Koester, S. Fiorini, G. Grom, L. Shepard, C. G. Stangor, B. Weiner, and T. A. McKay. 2017. Patterns of gendered performance differences in large introductory courses at five research universities. AERA Open 3, no. 4: 2332858417743754. doi: 10.1177/2332858417743754.

Mehta, J., and S. Fine. 2019a. High school doesn’t have to be boring. New York Times, March 30.

Mehta, J., and S. Fine. 2019b. In search of deeper learning: The quest to remake the American high school. Cambridge: Harvard University Press.

Perkins, D. 2010. Making learning whole: how seven principles of teaching can transform education. San Francisco: Jossey Bass.

Porter, C., and D. Serra. 2019. Gender differences in the choice of major: the importance of female role models. American Economic Journal: Applied Economics. doi: 10.1257/rct.2879.

Stevenson, B. and J. Wolfers. 2020. Principles of microeconomics. New York: Macmillan.

Theobald, E. J. et al. 2020. Active learning narrows achievement gaps for underrepresented students in undergraduate science, technology, engineering, and math. Proceedings of the National Academy of Sciences of the United States of America 117(12): 6476-6483. doi: 10.1073/pnas.1916903117. 
FIGURE 1: Share of Women and Underrepresented Minorities in Economics Courses at Harvard

\section{A. Women}

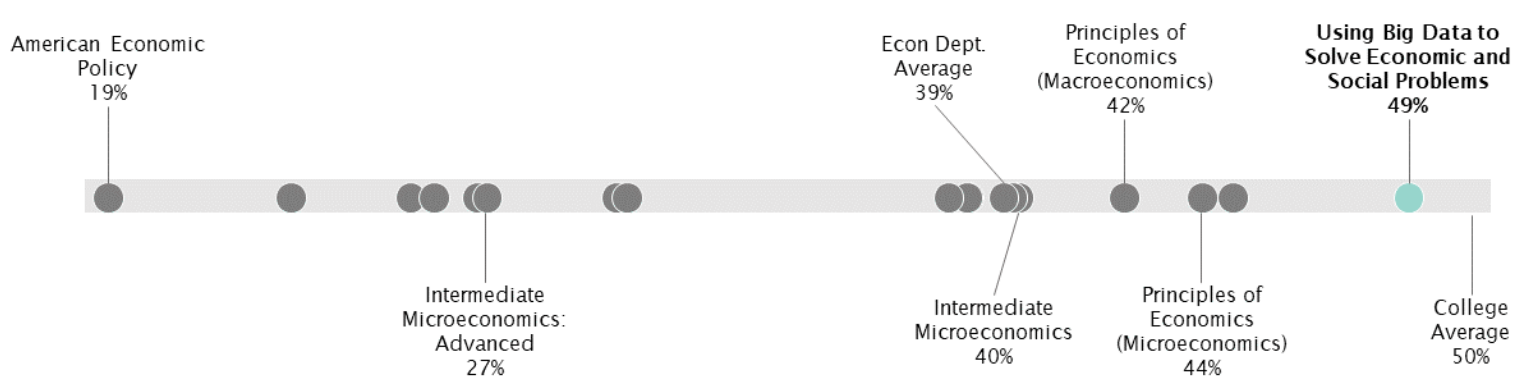

B. Underrepresented Minorities

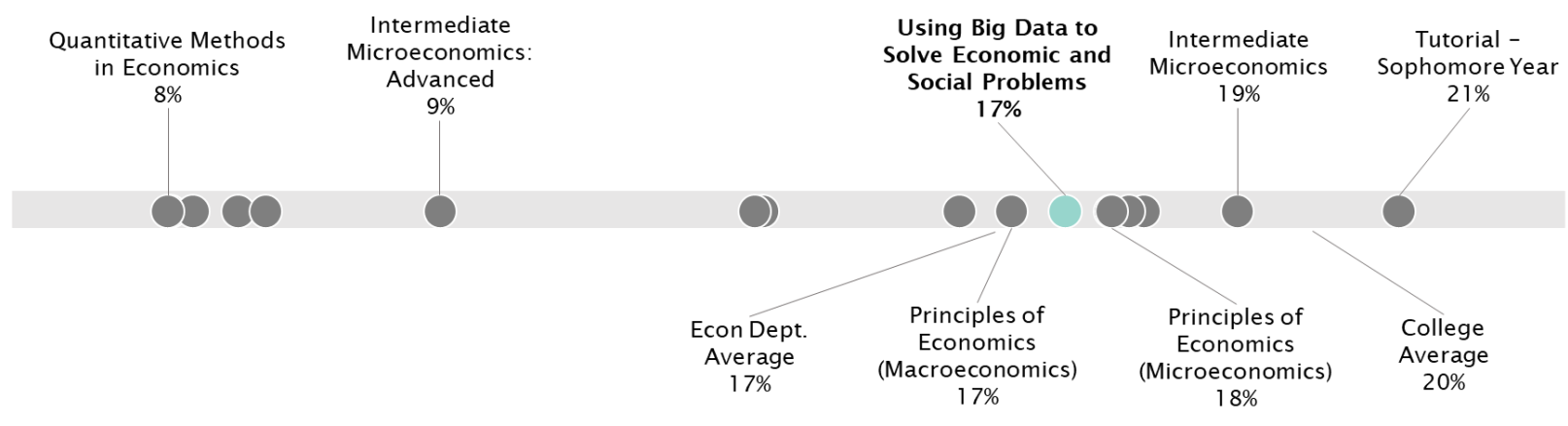

Notes: These charts show the shares of undergraduate women (Panel A) and African American and Hispanic (Panel B) students in undergraduate Economics courses at Harvard University. The enrollment statistics present means over academic years 2018-2019 and 2019-2020 and exclude summer terms. The sample is restricted to classes taught in both academic years with an enrollment of at least 20 students in each term. Observations with missing gender or ethnicity are excluded in the respective graphs. We also exclude senior thesis seminars from this analysis. The college averages shown in each panel show the share of women and underrepresented minorities pooling all undergraduate courses. 
FIGURE 2: Rates of Upward Mobility by Census Tract in Los Angeles from the Opportunity Atlas

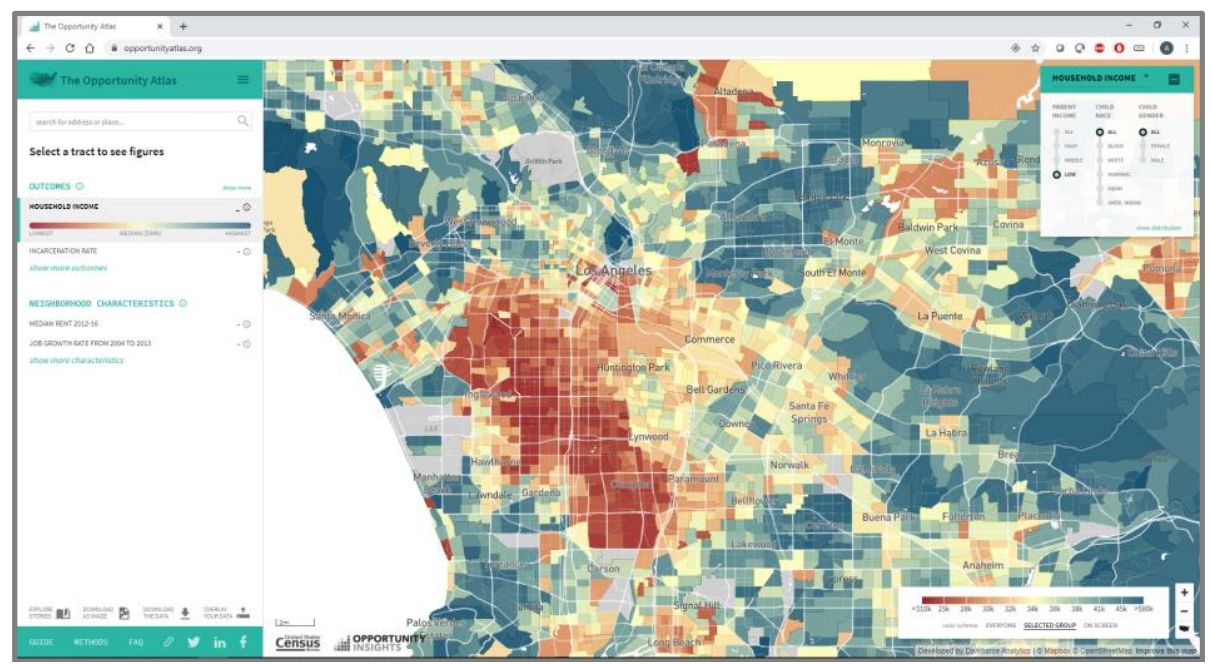

This map must be printed in color to be interpretable

Notes: This map shows estimates of upward income mobility drawn from the Opportunity Atlas by Census tract in the Los Angeles area (Chetty et al. 2018). Red colors represent areas with lower levels of upward mobility; blue colors represent areas with higher levels of upward mobility. Upward mobility is defined as the mean predicted household income rank in 2014-15 for children whose parents were at the 25th percentile of the national household income distribution (an income of \$27,000) for children in the 1978-1983 birth cohorts. This measure is estimated separately in each tract as described in Chetty et al. (2018). 
FIGURE 3: Differences in Gas Prices in Illinois/Indiana vs. Neighboring States Around Gas Tax Changes

A

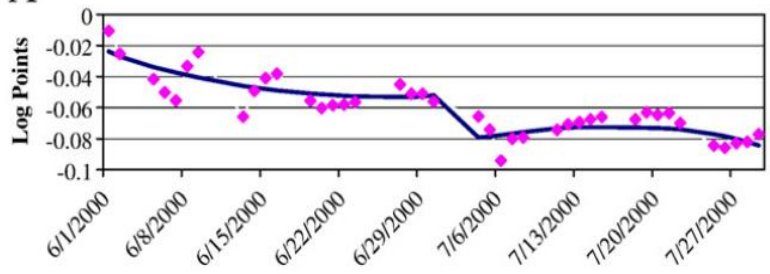

$\mathrm{B}$

Date

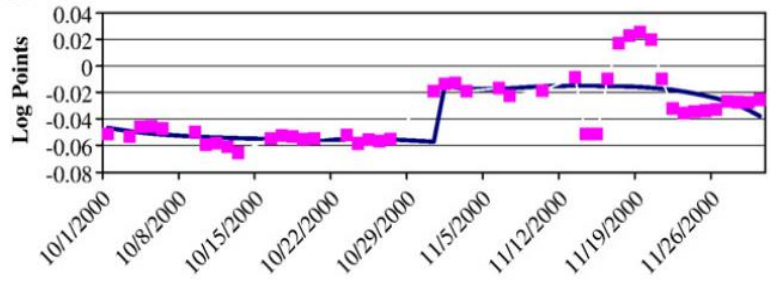

$\mathrm{C}$

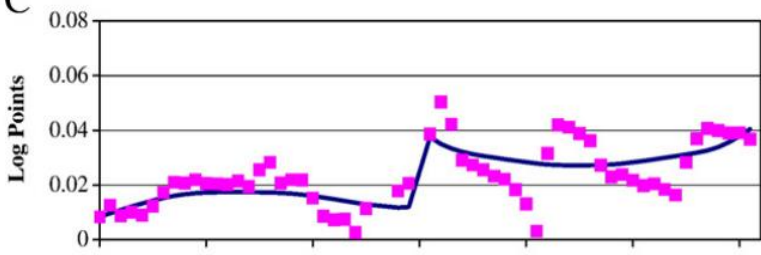

1-Dec-00 11-Dec-00 21-Dec-00 31-Dec-00 10-Jan-01 20-Jan-01 30-Jan-01

Date

Notes: This figure is taken from Doyle and Samphantharak (2008) and the notes that follow are adapted from that paper. It plots the difference in $\log$ (gas price) between Illinois/Indiana and neighboring states by time. Panel A reports results for the summer of 2000 when Indiana and Illinois suspended the sales tax on gasoline. Panel B shows the price differentials between Indiana and its neighbors around the time of the October 29th gasoline sales tax reinstatement in Indiana. Panel $\mathrm{C}$ reports these price differentials between Illinois and its neighbors around the January 1 gasoline sales tax reinstatement in the state. The size of the jump at the time of the tax change is equivalent to a difference-in-difference estimate of the effect of the tax change on retail prices. 
FIGURE 4: Effects of Premium Increases on Health Insurance Enrollment and Insurer Costs

Panel A: Average Monthly Enrollment by Income

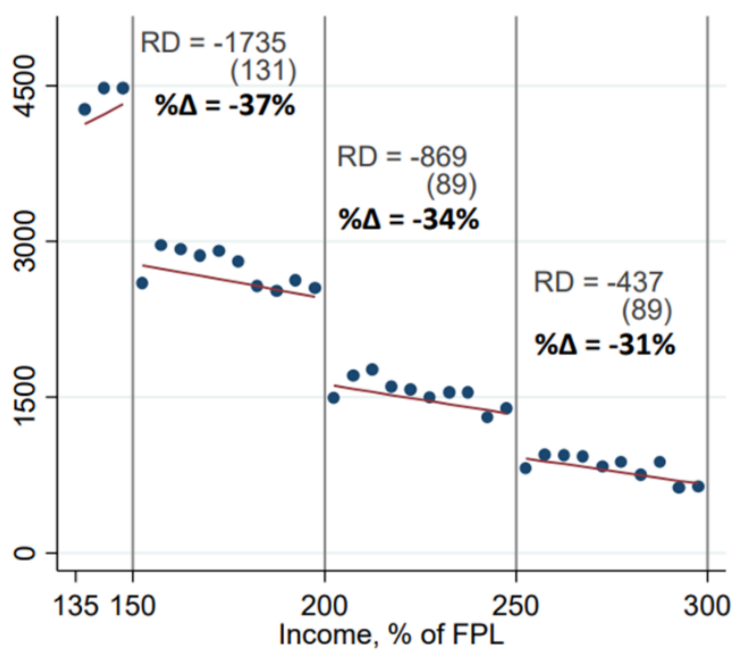

Panel B: Average Monthly Insurer Costs

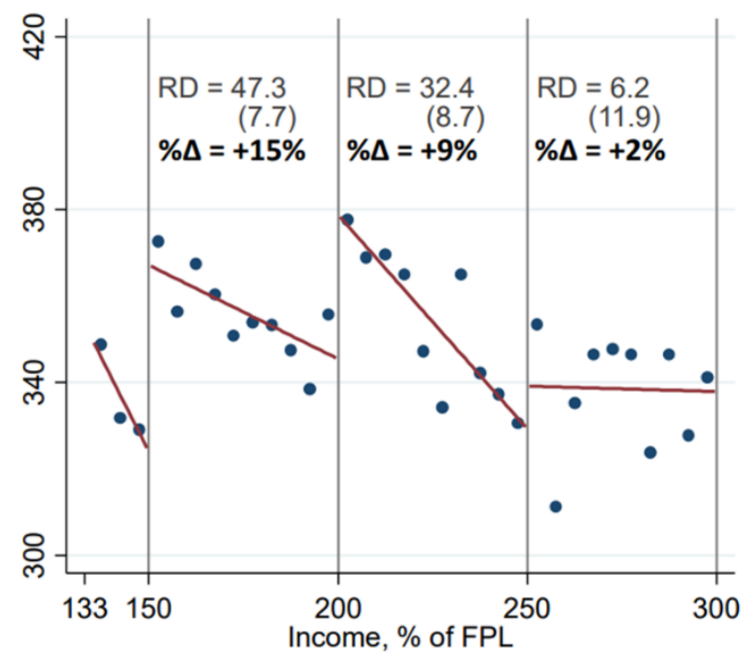

Notes: This figure is taken from Finkelstein, Hendren, and Shepard (2019) and the notes that follow are adapted from that paper. Health insurance premiums for plans offered through the subsidized Massachusetts health insurance exchange increase discontinuously at certain income thresholds, shown by the vertical lines (150 percent, 200 percent, and 250 percent of the federal poverty line). The figure shows how those premium increases affect enrollment rates and the types of people who choose to buy insurance. Panel A shows average enrollment rates in Massachusetts Commonwealth Care plans by income from 2009-2013. Panel B shows average insurer medical costs per month - a measure of the health of the insured population - across all CommCare plans over the same period. In each figure, the dots represent raw values for a 5 percent of federal poverty line bin, and the lines are best-fit lines from to those data. Regression discontinuity estimates and robust standard errors (in parentheses) are labeled just to the right of each discontinuity; percent changes relative to the value just below the discontinuity are labeled as $\% \Delta$ $=$. 